University of Nebraska - Lincoln

DigitalCommons@University of Nebraska - Lincoln

Faculty Publications, Department of Psychology

Psychology, Department of

June 1998

\title{
Effects of Weapons on Guilt Judgments and Sentencing Recommendations for Criminals
}

Richard A. Dienstbier

University of Nebraska-Lincoln, rdienstbier2@unl.edu

Scott C. Roesch

University of Nebraska-Lincoln

Ayumi Mizumoto

University of Nebraska-Lincoln

S. H. Hemenover

University of Nebraska-Lincoln

Roger C. Lott

University of Nebraska-Lincoln, rlott1@unl.edu

See next page for additional authors

Follow this and additional works at: https://digitalcommons.unl.edu/psychfacpub

Part of the Psychiatry and Psychology Commons

Dienstbier, Richard A.; Roesch, Scott C.; Mizumoto, Ayumi; Hemenover, S. H.; Lott, Roger C.; and Carlo, Gustavo, "Effects of Weapons on Guilt Judgments and Sentencing Recommendations for Criminals" (1998). Faculty Publications, Department of Psychology. 66.

https://digitalcommons.unl.edu/psychfacpub/66

This Article is brought to you for free and open access by the Psychology, Department of at DigitalCommons@University of Nebraska - Lincoln. It has been accepted for inclusion in Faculty Publications, Department of Psychology by an authorized administrator of DigitalCommons@University of Nebraska - Lincoln. 


\section{Authors}

Richard A. Dienstbier, Scott C. Roesch, Ayumi Mizumoto, S. H. Hemenover, Roger C. Lott, and Gustavo Carlo 


\title{
Effects of Weapons on Guilt Judgments and Sentencing Recommendations for Criminals
}

\author{
Richard A. Dienstbier, Scott C. Roesch, Ayumi Mizumoto, S. H. Hemenover, \\ Roger C. Lott, and Gustavo Carlo \\ Department of Psychology \\ University of Nebraska, Lincoln
}

\begin{abstract}
In Study 1, we explored whether guns presented for target shooting would lead subjects to assign longer prison sentences for crimes unrelated to the guns. Weapon-condition subjects recommended longer sentences than did control subjects, who had experienced equally energizing sports activities. In Study 2, subjects acting as jurors watched a police officer's videotaped deposition about a burglary arrest. Through the deposition, subjects in all conditions received identical information about the gun. However, some subjects heard the description of the gun taken from the burglar; some heard the description and saw the gun when it was placed on the evidence table near them; and some heard the description and handled the gun. Burglary-tool salience was manipulated similarly for another crime, but it had no effect. With increased weapon salience, subjects attributed more guilt and assigned longer sentences, but there were some differences between men and women, and we found unexpected positive relations between sentence severity and empathy. We discuss the theoretical and practical implications of our general finding that weapon salience elicits harsher criminal sentences.
\end{abstract}

Some years ago, several social psychologists investigated the causal relations between weapons and aggressive behaviors. Due in part to inconsistent findings in that literature, there has been a recent resurgence in interest in the "weapon effect." Our interests in the issue were sparked by those inconsistencies and by recent famous criminal cases in which weapons were presented or discussed as evidence (e.g., California $v$. Simpson). Specifically, we wondered about the effect of weapon salience on the guilt and sentencing judgments that judges and jurors make. As our Study 2 coincided with the continuing national debate on the ban of assault weapons (the Omnibus Crime Control Act of 1994), we used one of the banned weapons as a stimulus in Study 2. The purposes of our research were to address several theoretical questions and to address the practical issue of whether the well-studied effects of weapons on aggression would be observed when dependent measures involved guilt attributions tow ard and sentencing of criminals.

In their original study of the weapon effect, Berkowitz and LePage (1967) demonstrated that the presence of a pistol and

Requests for reprints should be sent to Richard A. Dienstbier, Department of Psychology, University of Nebraska, Lincoln, NE 68588-0308. E-mail: rad@unlinfo.unl.edu a shotgun, in contrast to neutral objects such as a badminton racket, influenced angered subjects to behave more aggressively toward an antagonist. That research was followed by many successful conceptual replications (e.g., Berkowitz \& Frodi, 1977; Caprara, Renzi, Amolini, D’Imperio, \& Travaglia, 1984; Frodi, 1975; Leyens, Cisneros, \& Hossay, 1976) as well as some replication failures (e.g., A. H. Buss, Booker, \& E. Buss, 1972; Cahoon \& Edmonds, 1984, 1985; Ellis, Weiner, \& L. Miller, 1971; Halderman \& Jackson, 1979; Page \& Scheidt, 1971) and even some actual reversals of the weapon effect (e.g., Fischer, Kelm, \& Rose, 1969).

Those mixed results prompted Carlson, Marcus-Newhall, and N. Miller (1990) to perform a series of meta-analyses to determine the parameters of the weapon effect. Carlson et al. reviewed 10 articles that used weapons (and other studies using different aggression-stimulating cues), several of which presented multiple studies and most of which presented multiple conditions. Despite finding "a nonsignificant, near-zero average effect-size" (p. 626), Carlson et al. concluded that aggression increases in the presence of weapons and attributed replication failures and reversals to evaluation apprehension and hypothesis aw areness.

Carlson et al. (1990) came to a series of conclusions about weapon-effect parameters and limitations that have relevance 
for our hypotheses. Carlson et al. noted that aggression levels were not affected by either the degree of weapon salience or the extent of relevance of the aggressive cue (usually weapon) to the recipient of the aggression. Carlson et al. also concluded that prior anger is not necessary for a weapon effect, and they noted that the status and power of target persons affected cue-stimulated aggression in logical directions (e.g., with lower aggression tow ard high-status individuals).

We expected that weapons would affect our written and symbolic dependent measures of guilt and prison sentencing as weapons had affected the physical aggression measures that predominate in the weapon literature. That expectation followed Berkowitz's (1993) theoretical perspective that aggression is "some kind of behavior, either physical or symbolic, that is carried out with the intention to harm someone" (p. 11). Berkowitz emphasized that it is irrelevant whether other goals are served by the aggressive act, such as protecting society from a criminal; in fact, aggression is of ten cloaked in a "moral purpose" (p. 27). Support for the utility of that perspective - that intended harm is necessary and sufficient to define aggression-comes from the demonstration that many different physical and symbolic acts correlate with one another and are similarly responsive to common aggressionrelevant manipulations even though those acts have little in common except that they harm individuals (Carlson, MarcusNewhall, \& N. Miller, 1989).

An important validity issue concerns whether responses on our sentencing measures indicate real aggressive tendencies when aggression is defined as behavior intended to harm another. In Study 1, we asked people for their recommended sentences for first-offense criminals guilty of a variety of crimes. In Study 2, subjects assigned guilt to, and made sentencing recommendations for, a single fictional criminal arrested with a gun at a crime scene; however, no pretense was made that sentences given in that role-play context would affect a real individual.

Generally, our sentencing measures are like typical attitude measures, reflecting attitudes tow ard offenders. Socialpsychological research over several decades has suggested that attitudes usually affect behavior. But, Carlson et al. (1989) provided a more specific analysis comparing questionnaire measures of aggression with physical laboratory measures, noting high correlations when the two types were obtained in the same research-that is, $r(35)=.71, p<.0001$. Carlson et al. also noted that written measures of aggression in general indicated larger effect sizes than behavioral measures did. As with the sentencing measures in our research, a large subset of the written measures analyzed by Carlson et al. included "instances in which the victim is unaware of the level of expressed aggression" (p. 386). That subset of measures also corresponded with physical measures. With similar analyses, Berkowitz and Donnerstein (1982) reviewed a variety of studies showing that aggressive behavior in nonlaboratory settings corresponds with various attitude measures and with aggressive physical responses in the laboratory.
This analysis therefore suggests meaningful positive relations among attitude measures of aggression, written measures obtained in laboratory settings, and behavioral measures obtained inside and outside laboratories. Based on those analyses, although we cannot be certain that responses to our sentencing questionnaires would reflect real behaviors in the voting booth or courtroom, substantial support exists for that conclusion.

\section{STUDY 1}

Although we used the sentencing of criminals as a dependent measure, Study 1 (unlike Study 2) was not designed to mimic any aspects of a criminal trial. Instead, it allowed us to determine that criminal-sentencing measures would be sensitive to a "weapon manipulation" and to address some theoretical issues.

Our hypotheses relate to but do not consistently agree with Carlson et al.'s (1990) observations.

We hypothesized that handling weapons would stimulate harsher sentences (in contrast to controls, who handled other sports equipment), even (as suggested by Carlson et al., 1990; Berkowitz, 1993, p. 53) when the guns had no connection with the crimes or criminals.

However, coinciding with Berkowitz's (1993, p. 83) view that hunters may be less likely to attach aggressive meaning to guns, we hypothesized that greater past use of guns would reduce their salience and decrease the weapon effect.

Reflecting our belief that weapons stimulate severe sentencing as a result of cuing ideas about aggression-rather than, or in addition to, misattributing tension evoked by weapons to a target person-we predicted an effect from a weapon manipulation that was no more energizing than the control condition. (For a similar perspective on aggressive "meaning" being elicited by cues like weapons, see Berkowitz, 1993, pp. 70, 83.)

We hypothesized that anger should enhance the weapon effect. This hypothesis simply follows from much of the early research findings and does not contradict Carlson et al.'s (1990) conclusion that anger is not a necessary condition.

Finally, based on traditional conceptions of hostility and empathy, we hypothesized that trait hostility would increase sentencing and that trait empathy would reduce sentencing.

\section{Method}

\section{Design and Overview}

In Study 1, we used a $2(\operatorname{Sex}) \times 2$ (Anger vs. Non-Anger) $\times 2$ (Weapon vs. Sport) between-subjects factorial design with same-sex groups of 4 subjects randomly assigned to the conditions. Non-anger subjects participated without delay in the weapon or sport condition; anger subjects were first 
delayed by a rude researcher for 15 min. ${ }^{1}$ Before departing, subjects completed measures of mood, sentencing of first-offense criminals, hostility, and empathy as well as the postexperimental questionnaire.

\section{Subjects}

Students from an introductory psychology course volunteered for participation in a study on "personality, attitudes, and sports preferences." After data from 4 suspicious subjects were eliminated (2 each from the weapon and sport conditions, to be described), 74 men and 89 women comprised the final sample.

\section{Dependent Measures}

Sentencing. For our main measure, subjects assigned prison sentences for 12 first-offense crimes ranging from drunk driving through drug offenses, vandalism, arson, robbery, rape, and manslaughter. For each crime, subjects chose a specific sentencing option from a 14-point scale, with sentences ranging from no prison time (1); through fine midscale gradations such as 2 years (4), 3 years (5), and 5 years (6); to a death sentence (14). Despite the wide range of crimes, Cronbach $\alpha$ s were .88 in Study 1 and .91 in Study 2, suggesting substantial within-person consistency in the sentencing of hypothetical criminals on this general sentencing measure.

Mood Adjective Checklist (MAC). The 21-item MAC used in both studies was based on the 3-item-per-factor short form developed by Nowlis and Green (1965). Cronbach $\alpha$ s for these 3 -item measures were satisfactory (.57 to .87 ).

Postexperimental questionnaire. Our postexperimental questionnaire was specific and detailed. For example, weapon subjects were asked whether they were "suspicious that the guns you saw were here for some purpose other than the purpose explained to you by the researcher." Subjects indicated the levels of their suspicions and when any suspicions were developed.

\section{Independent Measures}

Empathy. From a principal-components factor analysis of all items on Davis's (1983) Interpersonal Reactivity Index,

\footnotetext{
${ }^{1}$ With punitiveness as a dependent measure, our anger manipulation did not interact significantly with the weapon manipulation. However, these data do not affirm that anger had no effect: Our manipulation checks suggested only minimal and nonsignificant anger differences from our manipulation, and differences in punitiveness between the weapon and sport conditions were nonsignificantly greater for angry subjects. Given the inconclusiveness of these findings, although we include anger as a dimension in the analyses of our data, we omit further discussion of the anger manipulation.
}

Mehrabian and Epstein's (1972) Questionnaire Measure of Emotional Empathy, and Hogan's (1969) Empathy Scale, Weimer (1990) identified six factors. We based our measures on Weimer's analysis.

Cronbach $\alpha$ s for the six factors in our research were .53 (Emotional Control; 5 items), .55 (Distress at Another's Condition; 5 items), .74 (Emotional Concern for Others; 5 items), .76 (Fantasy Empathy; 5 items), .71 (Perspective Taking; 4 items), and .40 (Tolerance for Others; 5 items). ${ }^{2}$

Hostility. We used the Buss-Durkee (A. H. Buss \& Durkee, 1957) Hostility Inventory, but, as hostility was not a moderator or mediator of any effects in either study, no results are discussed.

Experience with and enjoyment of guns. Five items on hunting experience, enjoyment of hunting, enjoyment of hunting-related activities, target-shooting experience, and enjoyment of target shooting were created and combined into a single gun familiarity measure $(\alpha=.90)$ that was given only to the subjects exposed to guns.

\section{Procedures}

Upon arrival, the 4 same-sex subjects participating in each session were seated in a central waiting room surrounded by a suite of four smaller adjoining cubicles, each of which contained a different piece of sport or game equipment. Our cover story explained that we were studying how liking for spectator and participant sports related to social attitudes and personality. Thus, subjects were invited to look into each of the cubicles, and we misinformed them that they would eventually experience each of the cubicles. Two of the four cubicles contained materials relevant to our manipulations: The sport (control condition) cubicle contained equipment for football, basketball, and racquet sports; the weapon-condition cubicle contained fishing rods and two guns "for outdoor sports like fishing and hunting."

The 2 nondelayed subjects were sent directly into the sport and weapon cubicles, but the 2 subjects in the delayed (anger) condition waited about 15 min before experiencing those same conditions. When subjects entered the cubicles, they watched videos that explained that the procedure of watching sports on TV and handling sports equipment would equate their recent sports experiences.

Sport condition. After the introduction, each subject watched 3 min of Olympic gymnastics and, after being instructed to imagine being in the middle of an exciting football play, handled the football for $1 \mathrm{~min}$. The subject then watched $2.5 \mathrm{~min}$ of an exciting professional basketball "slam-dunk

\footnotetext{
The Tolerance for Others scale was subsequently dropped for low reliability.
} 
contest"; after receiving instructions to imagine participating in this contest, the subject handled the basketball for $1 \mathrm{~min}$.

Weapon condition. After the introduction, each subject watched a 3-min fishing program and then practiced casting with the fishing rods for $1 \mathrm{~min}$ while imagining catching fish. Then, a 1.5 -min target-shooting sequence showed a pistol being shot at a target in an indoor range. The subject was then asked to handle (in sequence) a .22 rifle and a Ruger Super Black Hawk .44 magnum pistol with an 8-in. barrel, sighting down the barrels of each while simulating target-shooting for $2 \mathrm{~min}$.

Activities common to the sport and weapon conditions. Following those activities, subjects were instructed by their videos to complete the mood and general sentencing measures as well as the questionnaires about their liking for the sports relevant to their cubicles. The sports questionnaires were included to verify the cover story about sport preferences and to obtain information from weapon subjects about gun familiarity.

After completing those measures, subjects left their respective cubicles to complete the hostility, empathy, and postexperimental questionnaires before being debriefed.

\section{Results}

\section{Weapon Effects on Sentencing}

As shown in Table 1, a $2(\operatorname{Sex}) \times 2$ (Anger vs. Non-Anger) $\times 2$ (Weapon vs. Sport) between-subjects analysis of variance (ANOVA) showed that weapon subjects assigned significantly longer sentences than did sport subjects to first-offense criminals. Although we had no hypotheses about sex differences, we noted that women gave nonsignificantly longer sentences than did men $(M \mathrm{~s}=57.3$ and 53.7 , respectively $)$, $F(1,155)=3.53, p<.07$.

To determine whether guns affected sentencing only when crimes would have logically included weapons, we divided the 12 crimes of the general sentencing measure into all logical categories and noted that the effect of guns was consistent across categories. Specifically, increased sentences following exposure to weapons were statistically significant for the nonviolent crimes but also for crimes committed with guns. The effect approached significance for violent crimes $(p<.16)$ and for crimes without guns $(p<.06)$.

\section{Weapon Effects on Mood}

A $2(\operatorname{Sex}) \times 2$ (Anger vs. Non-Anger $) \times 2$ (Weapon vs. Sport) multivariate ANOVA (MANOVA) with the six mood factors as dependent measures indicated a main effect for the weapon condition on mood, $F(7,142)=2.58, p<.02$, with univariate ANOVAs indicating that the presence of guns had substantial effects on four of the six mood dimensions measured. Specifically, as indicated in Table 1, guns resulted in significantly lower levels of "surgency" ("carefree," "playful," and "witty" items) and nonsignificantly lower vigor. Guns stimulated nonsignificantly more anger and significantly more anxiety. However, as noted in the lower section of Table 1, the increased anxiety from guns was entirely due to women.

To assess our success in equating energy (as conceptualized by Thayer, 1989) between the sport and weapon conditions, we created an energization score by subtracting the score for the mood of fatigue (based on "drowsy," "sluggish," and "tired" items) from that for vigor ("active," "energetic," and "vigorous" items). As seen in Table 1, energization was similar for the sport and weapon conditions; no other main or interaction effects approached meaningfulness or significance.

TABLE 1

Means, Standard Deviations, and Significance for General Sentencing and Mood Measures of Study 1

Condition

\begin{tabular}{|c|c|c|c|c|c|}
\hline \multirow[b]{3}{*}{ Measure } & \multicolumn{4}{|c|}{ Condition } & \multirow[b]{3}{*}{ Significance } \\
\hline & \multicolumn{2}{|c|}{ Weapon } & \multicolumn{2}{|c|}{ Sports } & \\
\hline & $M$ & $S D$ & $M$ & $S D$ & \\
\hline \multicolumn{6}{|l|}{ All Subjects } \\
\hline Sentencing ${ }^{\mathrm{a}}$ & $57.6^{\mathrm{b}}$ & 10.9 & $53.7^{\mathrm{c}}$ & 13.0 & $F(1,155)=4.36, p<.01$ \\
\hline Energization (range -9-9) & 3.51 & 4.70 & 3.94 & 5.16 & $F(1,154)=1, \mathrm{~ns}$ \\
\hline Surgency (range 4-12) & 7.10 & 2.65 & 8.04 & 2.47 & $F(1,151)=5.28, p<.03$ \\
\hline Vigor (range 4-12) & 8.57 & 2.91 & 9.35 & 2.98 & $F(1,154)=2.82, p<.10$ \\
\hline Anger (range 4-12) & 5.48 & 2.48 & 4.89 & 2.38 & $F(1,153)=2.36, p<.13$ \\
\hline Anxiety (range 4-12) & 5.75 & 2.47 & 4.97 & 2.10 & $F(1,151)=4.61, p<.05$ \\
\hline \multicolumn{6}{|l|}{ Women Only } \\
\hline Anxiety & 6.35 & 2.72 & 4.79 & 1.86 & Interaction, $F(1,151)=5.68, p<.02$ \\
\hline \multicolumn{6}{|l|}{ Men Only } \\
\hline Anxiety & 5.03 & 1.95 & 5.19 & 2.36 & \\
\hline
\end{tabular}




\section{Assessments of Arousal Misattribution}

To assess whether weapon-induced arousal might stimulate aggressiveness as reflected in harsh sentencing-either directly or through misattribution of arousal to the criminal sentencing activity - we assessed in detail the contributions of the arousal-relevant mood states to sentencing. Multiple regression equations were constructed to assess the weapon effect on sentencing after first removing sex and the separate and joint effects of energization and anxiety. Neither energization nor anxiety made a significant or substantial independent contribution to sentencing (e.g., when removed together, both $\beta$ s were less than .05 , ns). However, with sex, anxiety, and energization effects removed separately or together, the independent contribution of the weapon condition remained consistently significant (e.g., $\beta=.18), t(154)=2.24$, $p<.03$, after sex, anxiety, and energization effects were removed.

\section{Gun-Familiarity Effect}

We examined the gun familiarity effect on sentencing through a multiple regression procedure. The Gun Familiarity score, obtained only for weapon subjects, was a negative predictor of sentence length $(\beta=-.32), t(75)=2.01, p<.05$, with the sex effect removed. That effect remained relatively constant for subcategories of crimes such as crimes of violence and crimes against persons. However, gun familiarity was more strongly related to sentencing by women, $r(43)=$ $-.31, p<.04$, than by men, $r(36)=-.10$, ns.

\section{Empathy-Sentencing Relation}

Contrary to our hypothesis, harsher sentences corresponded with higher scores on each of the empathy factors previously described. That relation was significant for perspective taking $(\beta=.18), t(159)=2.30, p<.02$, with sex and weapon effects removed.

\section{Discussion}

These results suggest that experimental exposure to guns leads to harsh sentencing of criminals even when the guns are described as being for target use and are dissociated from both the crimes and the recipients of those sentences. This effect occurred despite our contrasting weapons with a control condition that elicited an equivalent level of arousal. Consistent with our hypothesis, long-term familiarity with weapons reduced the effect of guns on harsh sentencing, especially for women; contrary to our hypothesis, however, the perspectivetaking component of empathy correlated positively with sentence lengths.

The pattern of findings on the mood measures suggests that guns were associated with an overall increase in negative affectivity and an overall decrease in positive affectivity but with guns eliciting anxiety only in women. However, the finding that the weapon effect on sentencing remained after arousal-related mood effects were removed suggests that this effect cannot be attributed to arousal transfer or misattribution effects.

\section{STUDY 2}

Finding an effect of weapons that were dissociated from any criminal activity on criminal sentencing led us to hypothesize effects on guilt attributions and on sentencing of a specific criminal when the salience of that criminal's gun was manipulated. Subjects in all three salience conditions heard an identical description of the gun and of the conditions of its being discovered by the arresting police officer. Thus, we manipulated weapon salience while maintaining equal information about the gun in all three experimental conditions.

Although our expectation of weapon salience effects opposes Carlson et al.'s (1990) conclusions, these effects are consistent with the usual psychological emphasis (e.g., Berkowitz, 1993, p. 222) that stimuli that prime responses will not necessarily affect all individuals, so that more salient stimuli will have more effect. We hypothesized such an effect based on our assumption that the automatic assault weapon used in Study 2 would be very stimulating when held but less so when only described.

However, because of important procedural differences between Studies 1 and 2, we anticipated that our general measures of sentencing (of all criminals) and of mood would be less affected by our manipulations in Study 2 than they were in Study 1. That is, in Study 1, two guns were handled extensively (and fantasized about) in the weapon condition, but guns were never mentioned in the control condition; further, the anger manipulation appeared (albeit nonsignificantly) to enhance those between-conditions effects in Study 1. By contrast, in Study 2, between-conditions weapon salience differences were far less with all subjects exposed to weapons (through extensive description, through description plus sight, or through description plus handling); no anger manipulation was introduced that could enhance the weapon effects.

On the other hand, Study 2 subjects made guilt and sentencing judgments of the burglar who carried the gun. With that direct association of the weapon with the burglar, we expected the specific sentencing measure to be highly responsive to the weapon salience manipulation (as suggested by Berkowitz, 1993, p. 76).

Although we endeavored to present the burglar's weapon in a manner that would resemble the presentation of such evidence in a trial, the research itself makes no pretense of resembling a real trial. That is, our subjects heard only the police officer's deposition rather than a complete trial, they did not interact with one another, and we asked them to make 
sentencing recommendations in addition to decisions about guilt or innocence.

Our primary hypothesis for Study 2 was that greater salience of a crime-relevant weapon would lead to longer recommended sentences for the weapon-carrying criminal. As our measures of guilt were less sensitive, either-or measures, and as we continued to be interested in issues of sentencing, we considered the guilt measures to be secondary. We also hypothesized that our weapon salience manipulation would lead to between-conditions differences in mood, general sentencing, and perspective taking that would replicate those found in Study 1.

\section{Method}

\section{Design and Overview}

Two different crimes were presented to groups of 4 to 10 subjects acting as jurors. One crime was a burglary of a gas station; the other was a burglary of a department store (hereafter, store). There were two versions of each crime, and, whether the gas-station or the store crime was presented first, the first crime was always associated with burglary tools (hereafter, tools) and the second with the gun. The tools of the first crime and the gun of the second were presented at one of three salience levels to subjects. After each crime, mood, guilt, and sentence recommendations for the criminal were assessed. ${ }^{3}$

\section{Subjects}

Introductory psychology students volunteered to fulfill a research requirement. After data from 1 suspicious subject (in the weapon-pass condition) and 2 subjects who did not understand the deposition were eliminated, 68 men and 63 women comprised the final sample.

\section{Materials and Questionnaires}

Gun. A disarmed Tech-9 automatic machine pistol obtained from a local police department served as the weapon. This large gun was black and had a 15-bullet clip and a heat shield over the barrel. It belongs to the class of automatic assault weapons that were banned in the Omnibus Crime Control Act of 1994.

\footnotetext{
The tool versions of the two crimes were created to assess the alternative hypothesis that the salience of any substantial physical evidence would affect sentencing. Tool versions were created by substituting the tool descriptions for the gun description in the depositions and by substituting the actual tools for the gun in the pass and show conditions. No weapon was involved in the tool versions. Together, the hammer, the screwdriver, and the glass cutter approximated the bulk of the weapon. The $2(\operatorname{Sex}) \times 3$ (Tool Salience) between-subjects ANOVA revealed no significant main effects or interactions (all $F$ s $<2.0$ ) on guilt or punitiveness. Thus, descriptions of procedures and analyses of the tool crime are kept to a minimum here.
}

Videotaped depositions. The tool and gun versions of each gas-station and store crime were described in the videotaped 20-min depositions given by a real police officer undergoing questioning by a prosecutor (Lott, who had professional experience as a prosecutor). A "defense attorney" was present but played a minor role.

In the gas-station deposition, police apprehended the lone burglar in the gas station at night. A large bag of coins stolen from the vending machine was found with the burglar and was shown in the video. In the gun version of the crime, the gun was found on the burglar when the burglar was searched; the gun was removed from the burglar's belt by the police officer (but no burglary tools were mentioned). The gun or the tools were described at length on the videos, but neither appeared on camera.

In the store deposition, in response to a silent alarm, police discovered a pickup truck containing stolen electrical appliances. The burglar ran, but he fell and was apprehended. In the gun version of the crime, as in the gun version of the gas-station crime, the gun was found tucked in the belt of the burglar, but it had never been drawn or used by the burglar. As before, the gun or the tools were described at length but were not shown on camera. One of the stolen items, a boxed cordless telephone, was described and shown on camera.

Questionnaires. Our key dependent measures asked subjects to indicate "if on the real jury, how would you vote on the weapon violation charge" (gun crime only) and "on the burglary charge"; in each case, the choices were simply guilty and not guilty. After each guilt question, subjects indicated their degree of certainty of guilt on a 4-point scale. The sentencing measure asked subjects to assume the defendant to be guilty on both the weapon charge (gun crime only), and the burglary charge. The sentencing options were as presented on the general sentencing measure described for Study 1. The questionnaires for empathy, hostility, general sentencing, mood, and gun familiarity were as described in Study 1, with the postexperimental questionnaire tailored to fit Study 2 .

\section{Procedures}

Subjects were told that the purpose of the study was to examine how people on juries make decisions. They were randomly assigned to one of the three rooms, where they watched the first videotaped deposition, which was identical in all three conditions. The gas-station and store crimes were each presented first, as the tool crime, for half of the sessions. When mentioned on the video of the police officer's deposition, a bank bag full of coins (gas station) or a cordless phone (store) was passed to subjects, who in turn passed it from "juror to juror." Crime-scene photographs were also mentioned, but those were never shown to the subjects. These procedures were used to familiarize subjects with passing 
TABLE 2

Means and Standard Deviations for the Guilt and Specific Sentencing Measures of Study 2 as a Function of Weapon Salience

\begin{tabular}{|c|c|c|c|c|c|c|c|}
\hline \multirow[b]{3}{*}{ Measure } & \multicolumn{4}{|c|}{ Weapon Salience Condition } & & & \multirow[b]{3}{*}{ Significance } \\
\hline & \multicolumn{2}{|c|}{ Pass } & \multicolumn{2}{|c|}{ Show } & \multicolumn{2}{|c|}{ Describe } & \\
\hline & $M$ & $S D$ & $M$ & $S D$ & $M$ & $S D$ & \\
\hline \multicolumn{8}{|l|}{ All Subjects } \\
\hline Guilt (range 2-4) & 3.88 & 0.33 & 3.87 & 0.34 & 3.70 & 0.46 & $F(2,126)=3.15, p<.05$ \\
\hline Sentence & $6.60^{\mathrm{a}}$ & 2.33 & $6.38^{\mathrm{b}}$ & 2.09 & $5.47^{\mathrm{c}}$ & 1.87 & $F(2,124)=7.99, p<.001$ \\
\hline \multicolumn{8}{|l|}{ Women Only } \\
\hline Sentence & 7.30 & 2.16 & 5.90 & 1.71 & 5.40 & 2.26 & Interaction, $F(2,124)=5.02, p<.01$ \\
\hline \multicolumn{8}{|l|}{ Men Only } \\
\hline Sentence & 6.00 & 2.34 & 6.90 & 2.36 & 5.50 & 1.54 & \\
\hline
\end{tabular}

"exhibits" from person to person but also to establish that sometimes items mentioned would be passed and sometimes they would not. Thus, subjects were exposed to evidence presentation precedents designed to prepare them to experience without suspicion any of the three different levels of presentation of tools and (later) gun.

After the first deposition concerning the tool crime ended, subjects completed the dependent measures and were individually reassigned randomly to one of the three rooms, where they were exposed to the second (gun) crime.

As with the tool condition, the subjects in one of the three rooms were exposed to only the detailed verbal description of the Tech-9 machine pistol given on the video (describe condition). Those in another room heard the gun description and were simultaneously shown the gun by the experimenter; the gun was then placed on the "evidence table" (show condition), several feet in front of the subjects. The final third of the subjects heard the video description and simultaneously were handed the gun by the experimenter; subjects passed the gun "as an exhibit" from juror to juror (pass condition). In the show condition, and in the pass condition after subjects finished handling the gun, the gun was placed on the evidence table, where it remained in view throughout the remaining 7 min of the deposition. When the deposition ended and before subjects were given the dependent measures, all of the evidence on the table was removed. Subjects did not verbally interact during these procedures.

Subsequently, subjects completed the mood inventory and the guilt and punishment recommendations for the gun-carrying burglar. Finally, they completed the measures of general sentencing, empathy, and hostility and the postexperimental questionnaire, and they were debriefed.

\section{Results}

\section{Weapon Salience Effects on Guilt and Sentencing}

There were no effects for burglary location (i.e., store vs. gas station), so these data were combined. The guilt measures for the weapon and burglary charges were combined to increase power (neither was significant alone). We examined the combined measure with a $2(\mathrm{Sex}) \times 3$ (Weapon Salience) ANOVA. As indicated in Table 2, guilt differed significantly between weapon salience conditions, with the least guilt attributed when the gun was merely described. ${ }^{4}$

We examined the specific sentencing of the burglar similarly, but with a $2(\operatorname{Sex}) \times 3$ (Weapon Salience) analysis of covariance (ANCOVA) with the general sentencing measure used as a covariate. ${ }^{5}$ As noted in Table 2, a significant main effect for weapon salience was found, with longer sentences given with increased contact with the gun.

To explicate that finding, orthogonal contrasts were performed on the adjusted specific sentencing measure. Longer sentences resulted from the weapon-pass condition than from the describe condition, $F(1,127)=13.91, p<.001$; similarly, sentences were longer following the show condition than following the describe condition, $F(1,127)=3.82, p<.05$.

However, as show $\mathrm{n}$ in Table 2, the gun effect on sentencing was due mainly to the weapon having a greater effect on women than on men, as reflected in a significant $\operatorname{Sex} \times$ Weapon Salience interaction. Orthogonal contrasts showed that women in the pass condition gave significantly longer sentences than women in both the show, $F(1,41)=12.25, p$ $<.002$, and describe, $F(1,42)=20.43, p<.001$, conditions.

\footnotetext{
${ }^{4}$ Guilt was scored either not guilty (1) or guilty (2), so that the summary score for both charges could vary from 2 to 4 . The high means for this measure indicate that most subjects attributed guilt on both charges. When level of certainty was used as a multiplier of guilt, that measure was similarly statistically significant between weapon salience conditions, but it is not detailed here due to its redundancy with the guilt measure.

${ }^{5}$ There were no substantial or significant effects of weapon salience on the general sentencing measure, but women were significantly more punitive than men on that measure, $F(1,125)=10.33, p<.003$. Thus, in the Study 2 analyses, we treated punitiveness scores as dispositional and used them as a covariate to allow more powerful tests of weapon salience on specific sentencing of the burglar who carried the weapon. However, when we subjected our data to a $2(\operatorname{Sex}) \times 3$ (Weapon Salience) ANOVA without including general sentencing as a covariate, a significant main effect for the weapon condition and a significant $\mathrm{Se} \times \mathrm{W}$ eapon Condition interaction were still found.
} 
Men in the show condition gave significantly longer sentences than men in the describe condition, $F(1,39)=4.07, p$ $<.05$.

Finally, as in Study 1, women gave longer sentences on the general sentencing measure, $F(1,125)=10.33, p<.003$, and they tended to give longer prison sentences to this guncarrying burglar, as shown by a nearly significant main effect for sex, $F(1,124)=3.21, p<.08$.

\section{Weapon-Salience Effects on Mood}

To assess effects on mood, a 2 (Sex $) \times 3$ (Weapon Salience) MANOVA was examined with the six mood factors as dependent measures. No main effects were evident, and there were no substantial nonsignificant replications of the Study 1 mood effects of weapons.

\section{Perspective-Taking and Gun-Familiarity Effects on Sentencing}

A hierarchical multiple regression analysis was performed with specific sentencing as the criterion. Three main-effect vectors-two dummy-coded weapon salience conditions plus perspective taking - were entered at Step 1; the two two-way interaction vectors were entered at Step 2. Perspective taking interacted significantly with weapon salience. Analyses based on Aiken and West's (1991) procedures revealed that increases in perspective taking led to increases in sentencing only in the weapon-pass condition, $t(48)=3.76, p<.001$, and that perspective taking had no effect in either the show or describe condition.

As noted in Study 1, women with lower Gun Familiarity scores gave longer sentences, $r(59)=-.28, p<.05$. However, for men, specific sentencing was positively related to gun familiarity, $r(51)=.30, p<.05$.

\section{GENERAL DISCUSSION}

The weapon salience manipulations of Study 2 led to greater numbers of guilty verdicts. Similarly, the Study 2 results clearly show a weapon salience effect on sentencing achieved without the induction of anger. Thus, although weapon salience clearly affected the measures directly relevant to the gun-carrying burglar, the attenuated range of weapon salience between conditions in Study 2 probably accounts for failing to achieve effects similar to those of Study 1 on the general sentencing and mood measures.

\section{Theoretical Issues}

An obvious possible explanation for the results of any study that contrasts weapons with a no-weapon control is that weapons may stimulate harsher sentencing or aggression because weapon-stimulated arousal can be misattributed to (or displaced toward) an appropriate target. Finding a weapon effect in Study 1 (in which the two conditions were equally energizing) and in Study 2 (in which no significant betweenconditions mood effects were noted) suggests a more cognitively based explanation for the weapon effect.

Thus, we are led toward Carlson et al.'s (1990) position that weapon effects may result from the activation of relevant schemas. Our ideas about how such schema activation may relate to sentencing are entirely post hoc and speculative, as we anticipated neither the sex differences in sentencing nor the positive relation between perspective taking and sentencing that was found in Study 1 and (somewhat) replicated in Study 2. Bushman (1996) recently provided an interesting framework for considering these results.

Bushman (1996) measured trait aggressiveness (with a measure developed by A. H. Buss \& Perry, 1992) and aggression anxiety (Feshbach \& Singer, 1971; Feshbach, Stiles, \& Bitter, 1967) in male and female college students. Like our subject population, his was drawn from a large Midwestern university. Bushman noted that men from that population were considerably higher (about $1 S D$ ) in trait aggressiveness, whereas w omen were higher (about .5 SD) in aggression-anxiety. (Significantly, one of the items in the aggression-anxiety measure is "picking up a loaded gun makes me nervous.") Following his initial findings of stronger associations between aggressive terms by women and those high in trait aggressiveness, Bushman suggested that people differ in the degree to which their "cognitive associative netw orks" are like those of the perpetrators of aggression or those afraid of being victimized by aggression. In follow-up research (also Bushman, 1996), he found that aggressive stimuli were rated as both more aggressive and more frightening by women and by those high in aggression-anxiety.

Following Bushman's (1996) work and Berkowitz's (1993) similar observations that weapons are likely to evoke responses associated with either "fight or flight" (or both), we suggest that the weapons in our two studies were likely to evoke two types of schemas and/or fantasies-those associated with security and power (e.g., Bushman's "perpetrator networks") and those associated with weapon insecurity and threat (e.g., "victim networks").

Although Bushman (1996) did not study weapons, his findings with other aggression-evoking stimuli suggest that women are more likely to experience insecurity/threat in the context of weapons and that the aggressive quality of weapons will also be more evident to women. Consistent with those empirical observations, survey data presented by Berkowitz (1993, pp. 240-241, 392-393) suggest that these hypothesized sex differences in response to weapons are realistic, with far higher rates of women victimized by violence than perpetrating such offenses. And, according to Berkowitz (1993, pp. 48-49), both of these characteristics-associated more strongly with women, experiencing more aggressive meaning 
and more aggression anxiety-should stimulate aggressive responses. Therefore, it follows that there should be a consistent relation for women between increased weapon salience and increased aggression, as reflected in sentencing.

On the other hand, because men are more frequent users of weapons and perpetrate far more violence than women, the balance of schemas activated in men by guns may favor greater security/power schemas and reduced insecurity/threat schemas. Thus, the implications for men's responses (on sentencing measures) to weapon salience are less predictable than women's responses. In relation to these speculations, remember that men assigned (nonsignificantly) shorter sentences when they had the opportunity to handle the gun in Study 2 (pass condition) in contrast to their sentencing when they could see the gun but not handle it (show condition). Perhaps men feel less threatened when the gun is in their hands. Findings that women were made anxious by the guns (Study 1) and that the women lowest in gun familiarity (both studies) gave longer sentences support these speculations that schemas of insecurity/threat may mediate the positive relation between guns and sentencing.

Like our findings of sex differences, our Study 1 finding of perspective taking being associated with increased sentences for criminals surprised us, but Study 2 partially replicated those results. If people high in perspective taking actually do take the perspective of others, whose perspective would lead to greater criminal sentences? As we did not anticipate these results, our analysis is entirely post hoc.

In Study 2, the most obvious perspective to take was that of the arresting police officer, who described the gun-associated crime on camera for $20 \mathrm{~min}$ (the burglar was never shown). Further, the Tech-9 machine pistol used in Study 2 is an attention-focusing weapon, particularly when handled. It seems likely that more sympathy for the police officer who pursued a burglar armed with such a weapon would be evoked in those highest in perspective taking, especially after handling that gun.

\section{Applications}

These findings have real-life implications. First, they suggest that the salience of weapons that are presented as evidence in trials may have effects on guilt assessments and sentencing for criminals. That is, it appears that the balance between the "probative value" and the "prejudicial effects" of such evidence (see, e.g., Lilly, 1978) is affected by weapon salience, for our Study 2 results show that, even when information about the gun was equivalent between conditions, its increased salience apparently had a prejudicial effect.

Second, these results suggest that women may be more generally punitive than men toward criminals, but especially when guns are present. Further, criminal-sentencing individuals or groups who are less familiar with guns are likely to be maximally affected by the presence of weapons. Although our findings suggest that women who are unfamiliar with guns advocate longer sentences, our results suggest that men will probably also be affected by guns, but in uncertain ways.

Third, contrary to our initial hypothesis, individuals who are higher in the perspective-taking component of empathy are more likely to be affected by weapons, recommending longer sentences. However, women's granting longer sentences to criminals generally and in the presence of weapons is not due to higher perspective taking by women, for that measure and sex of subject make independent contributions to sentencing. These observations have relevance for jury selection.

As these practical implications are considered, we must consider the issue of discriminative validity. Remember that the results with tool salience in Study 2 showed clearly that sentencing would not be affected by salience manipulations of just any important piece of evidence. However, the question remains whether guilt and sentencing differences might be obtained from salience manipulations of other powerful and emotion-evoking stimuli. Should the "bloody glove" be passed from juror to juror? Berkowitz's (1993) perspective is clearly that a great variety of stimuli and conditions may evoke negative emotions and/or meanings that trigger aggressive responses. We agree and thus cannot argue here that weapons are qualitatively unique. They seem, however, to be unusually powerful and complex stimuli capable (as we have argued) of eliciting meanings associated with both insecurity/threat and security/power.

As a postscript to these conclusions, in March 1996 the U.S. Congress passed a resolution to eliminate the current ban on automatic assault weapons. A sponsoring congressman argued that his wife, home alone 5 days each week, should have the right to defend herself, presumably with an automatic assault gun. That resolution failed, but the issue subsequently became a significant issue in many campaigns during the fall elections of 1996. Although the issue is far from being resolved, those who advocate the ready availability of weapons have already won the day. Children living in our cities calmly tell investigative reporters that they can purchase guns at will, and they proudly display their weapons before television cameras; gunshot injuries are treated by public health officials as an epidemic. We may react with favor or disfavor to the possibility that weapons handled by jurors and judges (as they usually are, when offered in evidence) may have prejudicial effects on guilt assessments and sentencing. But the conclusion-that only harm to society results when similar dispositions result from guns being frequently in the hands of adults or children-seems inescapable.

\section{ACKNOWLEDGMENTS}

Scott C. Roesch is now in the Department of Psychology, University of California, Los Angeles.

We thank the many students who aided in the development of materials, acted as experimenters, and played the thankless 
role of "Jeri" in Study 1. For those activities, special thanks to Sandy Alwa, Julie Bengtson, Rodney Black, Jennifer Davenport, Jon Day, David Isaacson, Mark Jeffrey, Ruth Leinfellner, Bill Martin, Steve Snodgrass, and Wendy Zweifel. Thanks for help with running the study and data processing also to Cindi Halpin, Jennifer Massengale, Diane Richardson, and Barbara Valerian.

In Study 2, we were ably aided by Jeff Melby and Dion Buhman, who acted as experimenters, and Jaqueline McEwen, who helped in data processing. Our special thanks to Sergeant Jerome Thrane for his excellent professional depositions and to Lincoln Police Chief Tom Casady for the loan of the Tech-9 automatic machine pistol.

\section{REFERENCES}

Aiken, L. S., \& West, S. G. (1991). Multiple regression: Testing and interpreting interactions. Newbury Park, CA: Sage.

Berkowitz, L. (1993). Aggression: Its causes, consequences, and control. Philadelphia: Temple University Press.

Berkowitz, L., \& Donnerstein, E. (1982). External validity is more than skin deep: Some answers to criticism of laboratory experiments. American Psychologist, 37, 245-257.

Berkowitz, L., \& Frodi, A. (1977). Stimulus characteristics that can enhance or decrease aggression: Associations with prior positive or negative reinforcement for aggression. Aggressive Behavior, 3, 1-15.

Berkowitz, L., \& LePage, A. (1967). Weapons as aggression-eliciting stimuli. Journal of Personality and Social Psychology, 7, 202-207.

Bushman, B. J. (1996). Individual differences in the extent and development of aggressive cognitive-associative networks. Personality and Social Psychology Bulletin, 22, 811-819.

Buss, A. H., Booker, A., \& Buss, E. (1972). Firing a weapon and aggression. Journal of Personality and Social Psychology, 22, 296-302.

Buss, A. H., \& Durkee, A. (1957). An inventory for assessing different kinds of hostility. Journal of Consulting Psychology, 221, 342-348.

Buss, A. H., \& Perry, M. (1992). The Aggression Questionnaire. Journal of Personality and Social Psychology, 63, 452-459.

Cahoon, D. D., \& Edmonds, E. M. (1984). Guns/no guns and the expression of social hostility. Bulletin of the Psychonomic Society, 22, 305-308.

Cahoon, D. D., \& Edmonds, E. M. (1985). The weapons effect: Fact or artifact? Bulletin of the Psychonomic Society, 23, 57-60.

Caprara, G., Renzi, P., Amolini, P., D’ Imperio, G., \& Travaglia, G. (1984). The eliciting cue value of aggressive slides reconsidere $d$ in a personologi - cal perspective: The weapons effect and irritability. European Journal of Social Psychology, 14, 313-322.

Carlson, M., Marcus-Newhall, A., \& Miller, N. (1989). Evidence for a general construct of aggression. Personality and Social Psychology Bulletin, 15, 377-389.

Carlson, M., Marcus-Newhall, A., \& Miller, N. (1990). Effects of situational aggression cues: A quantitative review. Journal of Personality and Social Psychology, 58, 622-633.

Davis, M. H. (1983). Measuring individual differences in empathy: Evidence for a multidimensional approach. Journal of Personality and Social Psychology, 44, 113-126.

Ellis, D. P., Weiner, P., \& Miller, L. (1971). Does the trigger pull the finger? An experimental test of weapons as aggression-enhancing stimuli. Sociometry, 34, 453-465.

Feshbach, S., \& Singer, R. D. (1971). Television and aggression: An experimental field. San Francisco: Jossey-Bass.

Feshbach, S., Stiles, W. B., \& Bitter, E. (1967). The reinforcing effect of witnessing aggression. Journal of Experimental Research in Personality, 2, 133-139.

Fischer, D. G., Kelm, H., \& Rose, A. (1969). Knives as aggression-eliciting stimuli. Psychological Reports, 24, 755-760.

Frodi, A. (1975). The effect of exposure to weapons on aggressive behavior from a cross-cultural perspective. International Journal of Psychology, 10, 283-292.

Halderman, B. L., \& Jackson, T. T. (1979). Naturalistic study of aggression: Aggressive stimuli and horn-honking. A replication. Psychological Reports, $45,880-882$.

Hogan, R. (1969). Development of an empathy scale. Journal of Consulting and Clinical Psychology, 33, 307-316.

Leyens, J. P., Cisneros, T. J., \& Hossay, J. F. (1976). Decentration as a means for reducing aggression after ex posure to violent stimuli. European Journal of Social Psychology, 6, 459-473.

Lilly, G. C. (1978). An introduction to the law of evidence. St. Paul, MN: West.

Mehrabian, A., \& Epstein, N. A. (1972). A measure of emotional empathy. Journal of Personality, 40, 523-543.

Nowlis, V., \& Green, R. F. (1965). Factor analytic studies of the Mood Adjective Checklist (Tech. Rep. No. 11). LOCATION: PUBLISHER, Research Program on Mood and Attitude Change Research (Project No. NR 171-342).

Page, M. M., \& Scheidt, R. J. (1971). The elusive weapons effect: Demand awareness, evaluation apprehension, and slightly sophisticated subjects. Journal of Personality and Social Psychology, 20, 304-318.

Thayer, R. E. (1989). The biopsychology of mood and arousal. New York: Oxford University Press.

Weimer, D. (1990). The dimensions of empathy. Unpublished manuscript. 